\title{
Capsicum chinensis (Hot Pepper) Powder Larvicidal Activity Against Mosquitoes Larvae in Lafia Local Government Area, Nasarawa State, Nigeria
}

\author{
Ombugadu ${ }^{1 *}$, Micah EM ${ }^{1}$, Adejoh VA ${ }^{1}$, Odey $\mathrm{SA}^{1}$, Njila $\mathrm{HL}^{2}$, Nkup $\mathrm{CD}^{3}$, Pam VA ${ }^{1}$, Echor $\mathrm{BO}^{2}$, \\ Pam DD ${ }^{4}$, Ahmed $\mathrm{HO}^{1}$, Aimankhu $\mathrm{OS}^{1}$, Deme GG ${ }^{5}$, Uzoigwe NR ${ }^{1}$, Yohanna JA', Samuel MD', \\ Lapang $\mathrm{MP}^{4}$, Dogo $\mathrm{KS}^{1}$, Attah SA${ }^{1}$, Aliyu $\mathrm{AA}^{1}$, Ayuba $\mathrm{SO}^{1}$, Musa $\mathrm{M}^{6}$, Angbalaga $\mathrm{GA}^{7}$ and Mafuyai \\ $\mathbf{M J}^{8}$ \\ ${ }^{1}$ Department of Zoology, Faculty of Science, Federal University of Lafia, Lafia, Nasarawa State, Nigeria. \\ ${ }^{2}$ Department of Science Laboratory Technology, Faculty of Natural Sciences, University of Jos, Plateau State, Nigeria.
}

${ }^{3}$ Department of Biology, Science and Technology, Kurgwi, Qua'an Pan LGA, Plateau State, Nigeria.

${ }^{4}$ Department of Zoology, Faculty of Natural Sciences, University of Jos, Jos, Plateau State, Nigeria.

${ }^{5}$ State Key Laboratory of Ecology and Conservation, Institute of Zoology, Chinese Academy of Science, Beijing 100101, PR China.

${ }^{6}$ Department of Botany, Faculty of Science, Federal University of Lafia, Lafia, Nasarawa State, Nigeria.

${ }^{7}$ Department of Microbiology, Faculty of Science, Federal University of Lafia, Lafia, Nasarawa State, Nigeria.

${ }^{8}$ Department of Pest management Technology, Federal College of Forestry, Jos, Plateau State, Nigeria.

*Corresponding author: Ombugadu A, Department of Zoology, Faculty of Science, Federal University of Lafia, Nasarawa State,

Nigeria, E-mail: akwash24@gmail.com

\section{ARTICLE INFO}

Received: 幽 October 01, 2020

Published: 幽 November 11, 2020

Citation: Ombugadu A, Micah EM, Adejoh VA, Odey SA, Njila HL, et al. Capsicum chinensis (Hot Pepper) Powder Larvicidal Activity Against Mosquitoes Larvae in Lafia Local Government Area, Nasarawa State, Nigeria. Biomed J Sci \& Tech Res 31(5)-2020. BJSTR. MS.ID.005162.

Keywords: Capsicum chinensis; Mosquitoes larvae; Susceptible, Resistant; Lethal dose; Bio-larvicide; Lafia

\section{ABSTRACT}

Mosquitoes spread more diseases than other known arthropod and have shown resistance to conventional insecticides despite several control efforts, prompting the need to explore alternative control measures such as the use of bio-larvicides which are environmentally friendly. To this end, a study on larvicidal activity of the powder of Capsicum chinensis against mosquitoes larvae in Lafia Local Government Area, Nasarawa State, Nigeria was carried out through collection of wild field mosquitoes larvae from April to July 2018. Fresh Capsicum chinensis fruits were collected from farmlands and dried under room temperature and further processed to fine powder from which varying concentrations were used against the larvae. The larvae were exposed at 24, 48 and 72 hours, respectively. Anopheles gambiae larvae were susceptible (100\% mortality) to the various concentrations of the powder at the end of the 72 hours exposure period while Culex quinquefasciatus were resistant ( $0 \%$ mortality). There was a very high significant difference $(\mathrm{P}<0.0001)$ in mortality rate of An. gambiae larvae in relation to concentrations while there was no significant difference $(\mathrm{P}=1)$ in mortality rate of $C x$. quinquefasciatus across concentrations. $\mathrm{LD}_{50}$ and $\mathrm{LD}_{90}$ values for An. gambiae at 24 hours were $21.88 \mathrm{mg} /$ $\mathrm{mL}$ and $52.48 \mathrm{mg} / \mathrm{mL}$ respectively; $16.98 \mathrm{mg} / \mathrm{mL}$ and $38.90 \mathrm{mg} / \mathrm{mL}$ respectively at 48 hours and $13.80 \mathrm{mg} / \mathrm{mL}$ and $30.19 \mathrm{mg} / \mathrm{mL}$ respectively ay 72 hours. This study shows that Capsicum chinensis is a promising bio-larvicide for controlling An. gambiae. Also, $C x$. quinquefasciatus may possibly require higher multiple doses of Capsicum chinensis to influence mortality.

\section{Introduction}

Mosquitoes are considered insects of public health importance due to their ability to transmit a variety of diseases including West
Nile, dengue, yellow fever, lymphatic filariasis (elephantiasis) and malaria which is the leading cause of morbidity and mortality in 
Nigeria [1]. Malaria, which causes about 1.2 million deaths (majorly among pregnant women and children under five years old) is caused by Anopheles gambiae s. 1. [2]. Despite several efforts in controlling this vector, the medical and economic burdens caused by it continue to grow [3]. Currently, mosquito control strategies are fixated on the use of synthetic insecticides as constituents for Long Lasting Insecticide Treated Bed Nets (LLINs) and Indoor Residual Sprays (IRS) as methods recommended by the World Health Organization (WHO) [4]. Unfortunately, the success recorded by this strategy in terms of reduction of morbidity and mortality [5] is short-lived as mosquito resistance to insecticide has increased through time [6-11]. The failure in current control measures and the growing insecticide resistance is necessitating the search for newer and more effective control strategies [12]. The use of botanicals (plant-based products) is one of the best alternatives to synthetic insecticides $[13,14]$. This is because they offer a more environmentally friendly method of mosquito control [15] in that they have very weak adverse effect on non-target subjects [16] and are easily biodegradable [17]. Consequently, several plant species have been employed, worldwide, to control mosquito populations.

Capsicum chinensis (hot pepper) has both medicinal and insecticidal value and is used traditionally as medicine for treatment of various illnesses [18] including asthma, pneumonia, diarrhea, cramps, indigestion and toothache and it has been reported to possess repellent activity against insect pests of stored grains [19]. Extracts of Capsicum species have been proven as repellants to some species of some stored product beetles such as Sitophilus zeamais Motschulsky (Coleopteran: Curculinidae) and Tribolium castaneum (Herbst) (Coleopteran: Tenebrionidae) [20]. There are reports of using Capsicum as biopesticides against Alfalfa weevil larvae Hyper brunneipennis [21]. The toxicity of Capsicum species against insects is thought to be the effects of secondary metabolites such as alkaloids, saponins and flavonoid compounds [22]. Against this backdrop, this study was carried out to determine the larvicidal efficacy of the powder of Capsicum chinensis on mosquitoes' larvae in Lafia Local Government Area, Nasarawa State, Nigeria.

\section{Materials and Methods}

\section{Study Area}

The study was carried out in Lafia Metropolis with the following coordinate's $8^{\circ} 29^{\prime} 30^{\prime \prime} \mathrm{N} 8^{\circ} 31^{\prime} 0^{\prime \prime} \mathrm{E} / 8^{\circ} 49^{\prime} 16^{\prime \prime} \mathrm{N} 8^{\circ} 51^{\prime} 66^{\prime \prime} \mathrm{E}$. It is the capital and the largest town in Nasarawa State.

\section{Collection of Sample Plant}

Fresh ripe fruits of Capsicum were collected from cultivated farmlands on 5th April 2018 along Agyaragu-Tofa road in Lafia, Nasarawa State. Taxonomic identification of the plant was carried out in the Laboratory of the Department of Botany, Federal University of Lafia by Mr. Markus Musa. The plant samples were rinsed in clean water to remove dirt/debris, sliced into parts, then air dried under room temperature in the Laboratory of the Department of Zoology, Federal University of Lafia for 3 weeks. The dried plant was ground into fine powder in an electric grinder [23] then weighed on a weighing balance to get $20 \mathrm{mg}, 40 \mathrm{mg}$, $60 \mathrm{mg}$, $80 \mathrm{mg}$ and $100 \mathrm{mg}$ doses, respectively.

\section{Mosquitoes Larvae Collection}

First and second in star larvae of Anopheles and Culex mosquitoes were collected between April and July, 2018 from different breeding sites in Lafia using standard dippers and identified using identification keys by Gillies and de Mellion [24] and Burges and Cowan [25]. The larvae were kept in containers and allowed to acclimatize for 24 hours at room temperature before carrying out the test.

\section{Preparation of Bioassay}

The bioassay was prepared according to the recommended protocol of World Health Organization [26] for susceptibility. The larvae of Anopheles gambiae and Culex quiquefasciatus were exposed to varying doses (20mg, 40mg, 60mg, 80mg, and 100mg) of the powder of Capsicum chinensis. Each treatment (concentration) had four replicates and a control of two replicates. In each of the replicates, 25 first and second in star larvae were released into disposable $250 \mathrm{ml}$ bowls containing $100 \mathrm{ml}$ of distilled water and thereafter treatment was added. Control $(0 \mathrm{mg})$ was prepared as $100 \mathrm{ml}$ distilled water only. The knockdown rate of larvae was recorded after $5 \mathrm{mins}, 15 \mathrm{mins}, 20 \mathrm{mins}$, 30mins and $60 \mathrm{mins}$, respectively. Larval mortality was recorded in 24, 48 and 72 hours exposure period. Mortality was confirmed by gentle prick on the abdomen of the larvae with a needle $[26,27]$

\section{Test Analysis}

The interpretation of the mortality rate of Anopheles gambiae and Culex quinquefasciatus larvae is as described by WHO [26] where:

a) Mortality rate between $98-100 \%$ within the diagnostic time indicates susceptible.

b) Mortality rate between $80-97 \%$ suggest possible resistance.

c) Mortality rate $<80 \%$ indicates resistance.

\section{Percentage Mortality}

Unmoved and moribund larvae were recorded as dead.

$\%$ Mortality $=$ No. of Dead Larvae x 100\% / Total No. of Larvae Exposed

\section{Determination of $\mathrm{LD}_{50}$ and $L D_{90}$}

The mortality data were further subjected to probit analysis for estimating lethal dose values $\left(\mathrm{LD}_{50}\right.$ and $\left.\mathrm{LD}_{90}\right)$ using Finney method [28]. The 24, 48 and 72 hours $\mathrm{LD}_{50}$ and $\mathrm{LD}_{90}$ were determined 
through Microsoft excel regression analysis using the regression equation $(Y=a+b x)$.

\section{Data Analysis}

Data obtained was analyzed using R Console version 3.2.2. Pearson's Chi Square test was used to compare mortality rate of mosquitoes' larvae in relation to concentrations of $C$. chinensis powder. Level of significance was set at $\mathrm{P}<0.05$.

\section{Results}

Mortality Rate of Mosquitoes' Larvae in Relation to Concentrations of Capsicum chinensis Powder and Exposure Periods

A. Anopheles gambiae: An. gambiae larvae at 24 hours exposure period had highest mortality rate of $92 \%$ at $20 \mathrm{mg} / \mathrm{ml}$, $80 \mathrm{mg} / \mathrm{ml}$ and $100 \mathrm{mg} / \mathrm{ml}$ concentrations and no mortality $(0.00 \%)$ was observed in control $0 \mathrm{mg} / \mathrm{ml}$ as shown in Table 1 . Therefore, there was a very high significant difference $\left(\chi^{2}=91.442, \mathrm{df}=5\right.$, $\mathrm{P}<0.0001$ ) in mortality rate of An. gambiae larvae in relation to concentrations of $C$. chinensis powder. At 48 hours exposure period mortality rate of An. gambiae larvae was highest $98 \%$ at $60 \mathrm{mg} /$ $\mathrm{ml}$ while no mortality $0 \%$ was recorded in the control $0 \mathrm{mg} / \mathrm{ml}$ (Table 1). Thus, mortality rate of An. gambiae larvae in relation to concentrations of $C$. chinensis powder showed a very high significant difference $\left(\chi^{2}=96.835, \mathrm{df}=5, \mathrm{P}<0.0001\right)$. An. gambiae larvae mortality rate at 72 hours exposure period was $100 \%$ for all concentrations except for control $0 \mathrm{mg} / \mathrm{ml}$ which had $0 \%$ (Table 1). Hence, mortality rate of An. gambiae larvae in relation to concentrations of $C$. powder showed a very high significant difference $\left(\chi^{2}=100, \mathrm{df}=5, \mathrm{P}<0.0001\right)$.

B. Culex quinquefasciatus: No mortality was observed at 24 hours, 48 hours and 72 hours exposure period respectively in the larvae of $C x$. quinquefasciatus in relation to varying concentrations of $C$. Powder (Table 1).

Table 1: Mortality rate of mosquito's larvae in relation to concentrations of Capsicum chinensis powder and exposure periods.

\begin{tabular}{|c|c|c|c|c|c|c|c|c|c|c|}
\hline \multirow{2}{*}{ Species } & \multirow{2}{*}{$\begin{array}{c}\text { Time } \\
\text { (Hours) }\end{array}$} & \multicolumn{6}{|c|}{$\%$ Mortality across concentrations $(\mathrm{mg} / \mathrm{mL})$} & \multirow[t]{2}{*}{$\chi^{2}$} & \multirow[t]{2}{*}{ df } & \multirow[t]{2}{*}{$P$ value } \\
\hline & & $\mathbf{0}$ & 20 & 40 & 60 & 80 & 100 & & & \\
\hline \multirow{3}{*}{ An. gambiae } & 24 & 0 & 92 & 90 & 91 & 92 & 92 & 91.442 & 5 & $0.0001^{*}$ \\
\hline & 48 & 0 & 97 & 96 & 98 & 96 & 97 & 96.835 & 5 & $0.0001^{*}$ \\
\hline & 72 & 0 & 100 & 100 & 100 & 100 & 100 & 100 & 5 & $0.0001^{*}$ \\
\hline \multirow{3}{*}{ Cx. quinquefasciatus } & 24 & 0 & 0 & 0 & 0 & 0 & 0 & 0 & 5 & $1 \mathrm{~ns}$ \\
\hline & 48 & 0 & 0 & 0 & 0 & 0 & 0 & 0 & 5 & $1 \mathrm{~ns}$ \\
\hline & 72 & 0 & 0 & 0 & 0 & 0 & 0 & 0 & 5 & $1 \mathrm{~ns}$ \\
\hline
\end{tabular}

*: Significant

ns: Not significant

Lethal Dose $\left(\mathrm{LD}_{50}\right.$ and $\left.\mathrm{LD}_{90}\right)$ of Capsicum chinensis Powder that Exhibits Larvicidal Activity Against An. gambiae Larvae in Relation to Exposure Periods

The lethal dose of $C$. chinensis that will exhibit larvicidal activity against $50 \%$ and $90 \%$ respectively of An. gambiae larvae at 24 hours exposure period is $21.88 \mathrm{mg} / \mathrm{ml}$ and $52.48 \mathrm{mg} / \mathrm{ml}$ (Table 2).

Table 2: Lethal dose $\left(\mathrm{LD}_{50}\right.$ and $\left.\mathrm{LD}_{90}\right)$ of Capsicum chinensis Powder that Exhibits Larvicidal Activity against An. gambiae Larvae in Relation to Exposure Periods.

\begin{tabular}{|c|c|c|}
\hline \multirow{2}{*}{ Time (Hours) } & \multicolumn{2}{|c|}{ Lethal dose (mg/mL) } \\
\cline { 2 - 4 } & $\mathbf{L D}_{\mathbf{5 0}}$ & $\mathbf{L D}_{\mathbf{9 0}}$ \\
\hline 24 & 21.88 & 52.48 \\
\hline 48 & 16.98 & 38.90 \\
\hline 72 & 13.80 & 30.19 \\
\hline
\end{tabular}

Resistance/Susceptibility Profiles of Mosquitoes Larvae Exposed to $C$. chinensis Powder in Relation to World Health Organization Indices

At 24 hours exposure period, An. gambiae showed possible
Table 2 also shows that the lethal dose of $C$. chinensis required at 48 hours exposure period to exhibit larvicidal activity against $50 \%$ and $90 \%$ respectively of the An. gambiae larvae is $16.98 \mathrm{mg} / \mathrm{ml}$ and $38.90 \mathrm{mg} / \mathrm{ml}$. After 72 hours exposure period, the lethal dose of $C$. chinensis required to exhibit larvicidal activity against 50\% and $90 \%$ respectively of the An. gambiae larvae is $13.80 \mathrm{mg} / \mathrm{ml}$ and $30.19 \mathrm{mg} / \mathrm{ml}$ (Table 2). resistance across all concentrations mortality rate range from $91 \%$ to $92 \%$ while $C x$. quinquesfaciatus were resistant having $0 \%$ mortality rate. At 72 hours exposure period, An. gambiae were susceptible while $C x$. quinquesfaciatus were resistant. 


\section{Discussion}

The present investigation revealed that the powder of $C$. chinensis showed promising larvicidal efficacy against An. gambiae but may not be against $C x$. quinquefasciatus. This agrees with the studies by Abok et al. [14] and Dalis [29] who recorded that the leaf extracts of $H$. suaveolens were potent against the larvae of An. gambiae. However, this result did not conform to that of Madhumathy et al. [30] in which the ethanol extract of C. annum proved to be more effective on $C x$. quinquefasciatus than $A n$. stephensi in India. This could be due to the difference in species of Capsicum (C. chinensis - powder form and C. annum - ethanolic extract) used in the respective studies. The highest knockdown rate was observed at $100 \mathrm{mg} / \mathrm{ml}$ dose of Capsicum chinensis Powder used against An. gambiae larvae which possibly suggest that the highest concentration get to the target site of the larvae very fast to initiate larvicidal efficacy of $C$. chinensis powder. This is in accordance with the finding by Abok et al. [14] in a study on Hyptis suaveolens extract exhibits larvicidal activity against Anopheles gambiae larvae at the highest concentration. Knockdown was not recorded however for $C x$. quinquefasciatus across all doses of $C$. chinensis powder which possibly suggests them as tolerant to $C$. chinensis powder and affirms their survival in polluted water bodies.

The results obtained after 24, 48 and 72 hours exposure time in relation to An. gambiae demonstrated progressive increase in percentage mortality as concentrations increased. This buttresses Finney [28] assertion that larvicidal efficacy increased with an increase in concentration. The findings agree with studies by Odey [31] who investigated the larvicidal potency of the leaf powder of Millettia aboensis on the larval stages of An. gambiae and $C X$. quinquefasciatus and Kholhring [32] who investigated the mosquitocidal activity of M. pachycarpa on the larvae and eggs of Ae. Aegypti, recording peak mortality at the highest concentration after total exposure time. Chukwujekwu et al. [33] who investigated the anti-plasmodia diterpenoids from the leaves of $H$. suaveolens also recorded similar results. This result also coincides with findings of Olotuah [19] who conducted a laboratory evaluation of pesticidal activities of $H$. suaveolens against stored product pests Sitophilus oryzae, Sitophilus zeamais and Callosobruchus maculatus and recorded peak mortality at the highest concentration (100 mg/ $\mathrm{ml}$ ) after total exposure period.

The $100 \%$ mortality recorded in An. gambiae larvae in relation to the treatments after 72 hours exposure period possibly suggests time is a determining factor that should be considered to achieve a good susceptibility profile. This agrees with the findings by Abok et al. and Odey $[14,31]$ who showed that exposure duration played a major role in determining the resistance/susceptibility profiles in mosquitoes. After 24-hour exposure period, the larvae of An. gambiae showed possible resistance to the powder of $C$. chinensis across all doses. At 48-hour exposure period, they showed possible resistance at $20 \mathrm{mg} / \mathrm{ml}, 40 \mathrm{mg} / \mathrm{ml}$ and $80 \mathrm{mg} / \mathrm{ml}$ and $100 \mathrm{mg} / \mathrm{ml}$ doses of the plant powder but were susceptible to the plant powder at $60 \mathrm{mg} / \mathrm{ml}$. However, the larvae were susceptible to all doses after 72-hour exposure period. The resistance/susceptibility profiles recorded in relation to exposure periods was like the finding of Abok et al. [14].

The powder was shown to be more effective after 72 hours exposure time, with $\mathrm{LD}_{50}$ of $13.80 \mathrm{mg} / \mathrm{ml}$ and $\mathrm{LD}_{90} 30.19 \mathrm{mg} / \mathrm{ml}$. A possible reason for susceptibility recorded may be that the plant powder used up the dissolved oxygen available in the water, making it difficult for the mosquito species to survive [14] and also from the activity of capsaicin in the plant powder, which has significant lethal and anti-feedant effect on mosquito larvae [30]. Generally, An. gambiae larvae were completely susceptible to all doses while absolute resistance was observed in $C x$. quinquefasciatus larvae. Consequently, the finding by Meenakshi and Jayaprakash [34] showed that Anopheles larvae were more susceptible to the leaf extract of Rhizophora mucronata than Aedes larvae. Also, Kemabonta et al. [35] reported mortality of An. gambiae in relation to the insecticidal activity of essential oils for both P. nigrum (black pepper) and C. longa (turmeric) to be a $100.0 \%$. Furthermore, the habitat of Culex larvae suggests a possible reason for their resistance as they thrive in dirty, toxic and polluted water unlike Anopheles mosquitoes that prefer clean and clear water [25].

\section{Conclusion}

The result of this study clearly shows that Capsicum chinensis possesses larvicidal properties against larvae of An. gambiae while very high concentration of the powder of $C$. chinensis would be required to kill $C x$. quinquefasciatus. Hence, mosquitoes breeding success can be interrupted by pouring multiple doses of the powder of $C$. chinensis in stagnant water bodies as a direct control measure on vector populations. Also, it will be good to assess the impact of $C$. chinensis powder on non-target organisms.

\section{References}

1. WHO (2019). World malaria report. 232 pp.

2. Braack L, Hunt R, Koekemoer LL, Gericke A, Munhenga G, et al. (2015) Biting Behavior of African Malaria Vectors: 1. Where Do the Main Vector Species Bite on The Human Body? Parasit. Vectors 8: 76.

3. Wendy CV, Goddard J, Harrison B (2012) Identification Guide to Adult Mosquitoes in Mississippi. U.S.: Extension Service of Mississippi State University.

4. Hemingway J, Ranson H, Magill A, Kolaczinski J, Fornadel C, et al. (2016) Averting a Malaria Disaster: Will Insecticide Resistance Derail Malaria Control? Lancet 387(10029): 1785-1788.

5. Bhatt S, Weiss DJ, Cameron E, Bisanzio D, Mappin B, et al. (2015) The Effect of Malaria Control on Plasmodium falciparum in Africa Between 2000 and 2015. Nature 526: 207211.

6. Badolo A, Traore A, Jones CM, Sanou A, Flood L, et al. (2012) Three Years of Insecticide Resistance Monitoring in Anopheles gambiae in Burkina Faso: Resistance on the Rise? Malar. J 1: 232.

7. Oyewole IO, Kolawole, AA, Adeogun OC, Awololaaa S, et al. (2018) Susceptibility pattern of Anopheles mosquito to different classes of insecticides in selected communities in Ila-Orangun, Southwest Nigeria. 
International Journal of Mosquito Research 5(1): 106-111.

8. Awolola TS, Adeogun A, Olakiigbe AK, Oyeniyi YA, Okoh $\mathrm{H}$, et al. (2018) Pyrethroids resistance intensity and resistance mechanisms in Anopheles gambiae from malaria vector surveillance sites in Nigeria. PLoS ONE 13(12): e0205230.

9. Mwansat GS, Nanvyat N, Ombugadu A, Mafuyai MJ, Lapang MP, et al. (2019) Insecticide susceptibility status, resistance intensity and mechanism of pyrethroids resistance in An. gambiae s.l. mosquitoes from six Local Government Areas in Plateau State Nigeria. Abstract of the 50th Annual Conference of Entomological Society of Nigeria (ESN) Yola. ESN24/MVE07. P 66.

10. Oduola AO, Abba E, Adelaja O, Ande AT, Yoriyo KP, et al. (2019) Widespread Report of Multiple Insecticide Resistance in Anopheles gambiae s.l. Mosquitoes in Eight Communities in Southern Gombe North-Eastern Nigeria. Journal of Arthropod-Borne Dis 13(1): 5061.

11. Lynd A, Gonahasa S, Staedke SG Oruni A, Maiteki-Sebuguzi C, et al. (2019) Evaluation in Uganda Project (LLINEUP): a cross-sectional survey of species diversity and insecticide resistance in 48 districts of Uganda. Parasites Vectors 12(94): 1-10.

12. Radhika D, Ramathilaga A, Sathesh PC, Murugesan AG (2011) Evaluation of Larvicidal Activity of Soil Microbial Isolates (Bacillus and Acinetobactor sp.) against Aedes aegypti (Diptera: Culicidae) - The Vector of Chikungunya and Dengue. Proc Int Acad Ecol Environ Sci 1(3-4): 169178.

13. George DR, Finn RD, Graham KM, Sparagano OA (2014) Present and Future Potential of Plant-Derived Products to Control Arthropods of Veterinary and Medical Significance. Parasit. \& Vectors 7: 28.

14. Abok JI, Ombugadu A, Angbalaga AG (2018) Hyptis suaveolens Extract exhibits larvacidal activity against Anopheles gambiae larvae. Tropical Journal of Natural Product Research 2(5): 245-249.

15. Irungu LW, Mwangi RW (1995) Effects of a Biologically Active Fraction from Melia volkensii on Culex quinquefasciatus. Inst Appl Sci 2: 159-162.

16. Pavela R, Govindarajan M (2017) The Essential Oil from Zanthoxylum monophyllum a Potential Mosquito Larvicide with Low Toxicity to the Non-Target Fish Gambusia affinis. J Pest Sci 90: 369-378.

17. Pavela R (2018) Essential Oils from Foeniculum vulgare Miller as a Safe Environmental Insecticide against the Aphid Myzus persicae (Sulzer). Environ. Sci. Pollut. Res. Int 25: 1090410910.

18. Grubben GJH, El Tahir IM (2004) Capsicum annuum L. In: Grubben GJH, Denton OA (Eds.), PROTA 2: Vegetables/ Légumes. [CD Rom]. PROTA, Wageningen, the Netherlands.

19. Olotuah OF (2013) Laboratory Evaluation of Pesticidal Activities of Hyptis suaveolens in Pest Management. International Journal of Agricultural Research 8(2): 101-106.

20. Ho SH, Ma Y, Tan HTW, Halid H (1997) Repellency of Some Plant Extracts to the Stored Products Beetles, Tribolium castaneum (Herbist) and Sitophilus zeamais Motsch. Proceedings of the Symposium on Pest Management for Stored Food and Feed. Southeast Asian Regional Centre for Tropical Biology. BIOTROP 59: 209-215.

ISSN: 2574-1241

DOI: $10.26717 /$ BJSTR.2020.31.005162

Ombugadu A. Biomed J Sci \& Tech Res

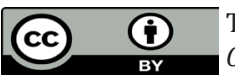

This work is licensed under Creative Commons Attribution 4.0 License

Submission Link: https://biomedres.us/submit-manuscript.php
21. Al-Doghairi MA, Hag EE (2003) Effect of Several Bio-pesticides on Alfalfa Weevil Larvae, Hyper brunneipennis. Pakistan Journal of Biological Science 6: 77781.

22. Bouchelta A, Boughdad A, Blenzar A (2005) Biocide Effects of Alkaloids, Saponins and Flavonoids extracted from Capsicum frutescens L. (Solanaceae) on Bemisia tabaci (Gennidus) (Homoptera: Aleyrodidae). Biotechnol Agron Soc Environ 94: 2569.

23. Raghavendra K, Singh SP, Sarala KS, Dash AP (2009) Laboratory Studies on Mosquito Larvicidal Efficacy of Aqueous and Hexane Extracts of Dried Fruit of Solanum nigrum Linn. Indian J Med Res 130(1): 74-77.

24. Gillies MT, de Meillon B (1968) The Anophelinae of Africa South of the Sahara (Ethiopian Zoogeographical Region). Publications of the South African Institute for Medical Research 54: 1-343.

25. Burgess NRH, Cowan GOA (1993) Colour Atlas of Medical Entomology pp. 143.

26.(2013) WHO. WHO Susceptibility Test Manual Instructions for Determining the Susceptibility or Resistance of Mosquito Larvae to Insecticides. WHO/VBC/75.583.

27. (2016) WHO Monitoring and managing insecticide resistance in Aedes mosquito populations interim guidance for entomologists pp.11.

28. Finney DJ (1971) Probit Analysis, $3^{\text {rd }}$ (edn.), London: Cambridge University Press. 25325.

29. Dalis DY (2016) Larvicidal Potency of Hyptis suaveolens Leaf Extract against Malaria Vector, Anopheles gambiae. M. Sc. Thesis submitted to the Department of Zoology, University of Jos, Plateau State, Nigeria (Unpublished data).

30. Madhumathy AP, Aivazi AA, Vijayan VA (2007) Larvicidal efficacy of Capsicum annum against Anopheles stephensi and Culex quinquefasciatus. J Vet Borne Dis 44(3): 223-226.

31. Odey SA (2017) Bio-Efficacy of the Leaf Extract and Powder of Millettia aboensis Against Larval Stages of Anopheles gambiae and Culex quinquefasciatus in Lafia, Nasarawa State. M. Sc. Thesis submitted to the Department of Zoology, Federal University of Lafia, Nasarawa State, Nigeria (Unpublished data)

32. Kholhring L (2011) Mosquitocidal activity of Millettia pachycarpa on the larvae and eggs of Aedes aegypti. Scholars Research Library. Annals of Biological Research 2(3): 217-222.

33. Chukwujekwu JC, Smith P, Combes PH, Mulholl, Vanstanden J (2013) Antiplasmodial diterpenoids from the leaves of Hyptis suaveolens. Journal of Ethnopharmacology 102(2): 295-297.

34. Meenakshi SV, Jayaprakash K (2014) Mosquito larvicidal efficacy of leaf extract from mangrove plant Rhizophora mucronata (Family: Rhizophoraceae) against Anopheles and Aedes species. Journal of Pharmacognosy and Phytochemistry 3(1): 78-83.

35. Kemabonta, KA, Odediran, OI, Ajelara KO (2018) The Insecticidal Efficacy of the Extracts of Piper nigrum (Black Pepper) and Curcuma longa (Turmeric) in the Control of Anopheles gambiae Giles (Dip, Culicidae). Jordan Journal of Biological Sciences 11(2): 195-200.

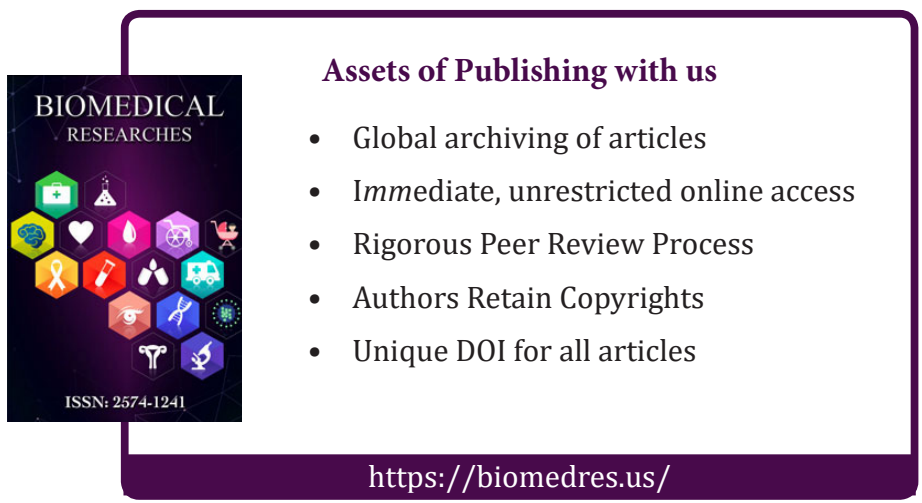

